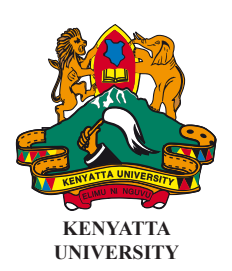

ISBN 1563-1028

\section{CHEMCHEMI}

International Journal of Humanities and Social Sciences

\title{
THE QUEST FOR DEVELOPMENT TRANSFORMATION IN NORTHERN UGANDA
}

\author{
Eric Awich Ochen
}

\begin{abstract}
This paper discusses the dynamics of development agencies' support to conflict-affected northern Uganda in the period between 2006 and 2012, and its implications for post-conflict recovery and development. The study utilizes a mainly qualitative approach incorporating in-depth interviews with key informants, focus group discussions and secondary data review. Data was analyzed thematically using template analysis methods. Findings show that, at the height of the northern Uganda conflict between the year 2001 and 2006, the region was a beehive of 'development agencies' activities, with scores of development agencies supporting the affected communities. These agencies (including the UN agencies, civil society organizations and even private sector agencies complemented government efforts in the resettlement and reintegration process for communities affected by the conflict. Yet queries remain. For example, have the interventions been done right and conceived within the right assumptions? This paper, therefore, analyses the trends and dynamics of both state and non-state actors' interventions within northern Uganda, especially the post-2006 period. It is posited that donor priorities, interests and preferences other than government and non-state actors' interventions and situation of the target groups seem to be the driving force behind programme planning, funding and implementation. This revelation presents important lessons and experiences to actors and social planners working in the area of post-conflict development and reconstruction. The main lesson drawn from this study is that government and indigenous agencies should proactively take the initiative in community rebuilding process and not extensively rely on foreign donors.
\end{abstract}

Key words: Conflict, post-conflict recovery and development, state, non-state actors.

\section{Contextualizing Development in Northern Uganda}

Northern Uganda is currently emerging from the prolonged period of conflict in which it has been engulfed since 1986. Over the period of the conflict, some 20,000 people have been killed, and over two million displaced (US Institute of Peace, 2010), many of whom were relocated to internally displaced persons camps (idpc). These camps were established in the mid-1990s following calls from the Ugandan government for their formation as means of protecting the general population from the LRA. By 2005 the number of such camps had grown to 250 , housing around 1.8 million people. Recent studies have suggested that that although three-quarters of the internally displaced persons (IDPs) have returned to their homes, some 25 percent of the population of northern Uganda (especially Acholi sub region) still languishes in IDPCs (Norwegian Refugee Council, 2010).

over the years, various armed groups have operated in northern Uganda with the major ones being the Uganda patriotic democratic army 1986-1988, Alice Auma Lakwena group (1986-1988), and the LRA (1988- present). Of all the fighting forces in, the LRA have been the most brutal and long lasting, with varying intensity over the years. While commentators and scholars have advanced various reasons for the origins and continuity of the conflict, what is clear is that the conflict started in 1986 and has not formally 
ended. Active military engagements between the UPDF and the LRA have been transferred to the Central African Republic, Sudan and the Congo, with northern Uganda virtually peaceful. There is however one agreement among scholars that the northern conflict is complex and is situated within the geo-political forces within the region and the nature of domestic politics within Uganda (Omach 2010a; Dolan 2006).

Political commentators have noted that the nature of the domestic politics in Uganda (weak state) and the overall approach to governance is at the core of the northern Uganda insurgency (Omach 2010a; Omara-Otunnu, 1992) although the brutality of the NRA has generally been regarded as the spark that set off the northern conflict. according to Omach (2010a): "the armed conflict in northern Uganda is rooted in Uganda's domestic politics and the problem of state making and nation building, including the lack of national integration and failure to build consensus on the role of the constituent groups in national politics" (Omach, 2010a, p. 187). This observation implies that there is a failure on the part of the ruling elite to effectively and sustainably involve various constituent groups in government, thereby creating both overt and covert revolts.

Other commentators have noted that the failure at state building is the result of desires to centralise and monopolise state power (Omach, 2010b; Oloka-Onyango, 2001). If the state was strong, inclusive and accountable, perhaps the conflict in northern Uganda would not have occurred. It is suggested however that when states are weak, they often lack "domestic, political and social consensus" Omach (2010a, p.289). Such struggles are at the root of armed conflict and the incessant insurgencies over the years.

The marginalization of the north by the NRM administration has also been advanced as an explanation of the conflict (Bainomugisha, 2011; Maina, 2010; Refugee Law Project, 2004). This however also relates to the weakness of the state and its inability to pursue uniform and equitable national development. Bainomugisha argues that economic marginalization is at the root of the conflict in northern Uganda. Indeed commentators have noted that such economic, political and social marginalisation has created two countries in one (the creation of two Ugandas: the prospering south and the stagnating north). With many of the successive post-colonial governments, neo-patrimonial politics proved significant obstacles in redressing the colonial imbalances within the country, especially the situation in the north (Omach 2010a, 2010b; Omara-Otunnu, 1987, 1992). Even Uganda's longest post-independence government, the NRM, has failed either by omission or design "to priorities the development of northern Uganda as a conflict management tool" (Bainomugisha, 2011, p. 173). Currently however there is virtual peace within the region although the theatre of confrontation between the LRA and the UPDF has changed to the jungles of the Congo and Central African Republic, with northern Uganda currently peaceful.

Taking a case study of formerly abducted child mothers, I argue that while development agencies have been supportive of the reintegration process of these young people and other children affected by the conflict, these interventions have been bedecked with significant problems and challenges. Moreover, a critical analysis of most of these services suggests that their design did not adequately factor in gender issue and the experiences of the young women, more specifically. This is even more true in the case of formerly abducted young mothers who returned with children and faced multiple challenges, yet conscious considerations of their unique experiences was lacking. I explore the limitation of the interventions from its conceptualisation, design and strategies, which were significantly constrained. Such imitations may have been occasioned in part by failure to adequately consult the young women and factor in their interest.

Indeed as will be shown later, many of these interventions focused on the young women as children or girls and boys without a realisation of their changing gender roles, the problems they were likely to face as young women, and child mothers in a context which was just recovering from conflict and laden with strong gender nuances and biases. I argue that at the backdrop of these interventions is an attempt to paint the young women or interned project recipients as passive participants yet it is imperative that an agential focused analysis is made of their situations. This could be the basis of design and planning intervention so that the current short-termism and adhoc intervention planning are avoided in a transitory development context. It is these challenges and development issues that this paper explores. I have used formerly abducted child mothers as they remain the most vulnerable and more likely to suffer more reintegration challenge (Ochen, 2013; Angucia, 2010). Unlike other formerly abducted children, young mother have children who face increasing difficulty to cope in the absence of their fathers. Northern Uganda thus presents a good case for a community in transition from an active political emergency to a recovery and 
development one. It thus presents an opportunity to learn from a security sector reform and interventions to an inclusive post-conflict development programming. The key research question this study attempts to answer is: Has the interventions by government and non-governmental agencies in northern Uganda adequately addressed the aspirations and situations of the formerly abducted child mothers?

\section{Methodology}

This qualitative study was conducted between September, 2011 and February, 2013 in Gulu and Amuru districts. Forty six (46) formerly abducted young women between the age of 17 and 25 who returned with children born to them while in rebel captivity formed the core of the study. All these young women were abducted at age 9-11 as young girls themselves. Data was also collected from 19 key informants, across two districts of Gulu and Amuru districts. These key informants are people who by virtue of their positions had direct contacts with the research participants. These range from local leaders in the community, staff of non-governmental organisations and relevant government departments providing one service or another to the participants and other opinion leaders and development activists. Similarly, the researcher carried out a total of 16 focus groups during field data collection with the members of the community including persons working as community resource persons providing child protection and other support services at community level. This was to capture community perspective on the services and reintegration experience of the formerly abducted young women. The aim of the study was to capture the unique programming and reintegration experience of the young women and so the necessity of conducting narrative interviews with them.

The textual data from the field interviews were then subjected to a form of thematic analysis called template analysis (TA) to categorise, organise and draw meanings from the texts. The main strategy in TA is to determine the main themes for the study and derive the subsequent smaller level themes in a nested but orderly hierarchical way (King, 2012). In our case, an initial template was developed by utilising information from the main research questions and the interview guides which were in place prior to the commencement of fieldwork to determine initial codes. Manual analysis was relied upon in ordering the information on an acceptable template. This was later enriched by considering the themes emerging from the data. Further adjustment to the template was made during the data transcription process when more codes were applied to the initial template and modification made to the original template (King 2012). Data interpretation was however guided by the research aims, the research questions and theoretical frameworks and assumptions. During the process of analysis the researcher paid close attention to the meanings and nuances that the research participants brought out.

\section{Feminist Perspectives and Research on Children in Armed Conflict}

Considering that the formerly abducted child mothers are first of all girls and women interacting in a complex relationship with the men in their lives from captivity up to the post-reinsertion communities; it is important to place the outcome of the analysis against a feminist lens and research perspective. There is suggestion that the power imbalances inherent in the Acholi community, where women and girls take a backseat (Okello and Hovil, 2007), is one of the fundamental reasons for their apparent exploitation in the current system. Although it is also worth pointing out that boy children have equally been the target of exploitation by fighting and competing forces, the dynamics of the experiences of the girls and young women in the context of the war merits special attention. It is also important to note that the majority of the girl children were also abducted by male rebel soldiers. War, culturally and historically has been a male (adult) affair in most of the cases.

Recent studies on children affected by armed conflict have indicated that the greater composition of the rebels as well as its top leadership is male. Therefore from both their bush/captivity experiences and their efforts at reconstituting their lives in the community, gendered power imbalances are at play. Studies from Eastern Uganda, Sierra Leone, Angola and Mozambique both point out the gendered power imbalances and exploitation of the girl children (Frerks et al., 2005; Mazurana and McKay, 2004; De Berry, 2004). It is probable that power structures might be at play in the community's 'protection' systems and structures which might in turn further alienate women and girls from the needed psychosocial support, thereby constraining reintegration programmes (UNICEF, 2005, p.203). 
Taking a position that feminism focuses on the question of the woman and her place in society, McLaughlin (2003) identifies different branches and thinking of feminism often influenced by other socio-political theories and ideas. These were indicated as Marxist/socialist feminism, liberal feminism as well as radical feminism. It is suggested that the attribution of what is or is not feminist "rests on claims rather than facts" and there is no universal acceptability of a definition (Ramazanoglu and Holland, 2002, p.146). This study, however, is not about feminism or evaluation of the different forms and dimensions of feminisms, but about using feminist ideas to illuminate, contextualise and advance the research argument. While different feminist scholars provide divergent perspectives on the ultimate aim of feminist social research, Ramazanoglu and Holland (2002, p.147) argue that the main aim for feminist social research is to "give insights into gendered social existence that would otherwise not exist" but not "to score points for political correctness or to attain methodological purity".

It is thus important to note that a research project cannot be labelled feminist simply because it investigates gender or gendered social lives. According to Ramazanoglu and Holland (2002, p.147) "research projects can be thought of as feminist if they are framed by feminist theory and aim to produce knowledge that will be useful for effective transformation of gendered injustice and insubordination". And this is the position taken in this study: to what extent can we unravel the gendered injustice and insubordination inherent in the experiences of the girls and formerly abducted child mothers, even in the reintegration process, as they access particular services? It is my belief that feminist perspective in this regard will tease out these issues from the points of view of the girls/young women and thus enable a better appreciation of their experiences.

I have also drawn on the feminist theory of intersectionality (Jones, 2009; Crenshaw, 1994) to enable me better appreciate the experiences and situated identities of the child mothers as they negotiate their ways through their captivity and later resettlement, rehabilitation and reintegration processes. While intersectionality was initially applied to black women's experiences of oppressions within a racialised American society, it has since been used to appreciate and explore women's experiences in many other different contexts. It has aided the analysis of how gender intersects with many other factors (including socio-cultural ones) to create a situation of rights violations for the women and children (see also Jones, 2009). I find the theory of intersectionality relevant and useful in understanding the complex experiences of the formerly abducted child mothers' right from abduction through captivity and in the post-bush situations in the return period.

In applying intersectionality theory to the experiences of the African child/woman, I investigate those positions and situations of the girls and child mothers which act and intersect to enhance their oppression or exclusion from normal society's life or violations of their rights. It is important to understand how FACM's experiences of conflict, among other identity factors, intersect with their socio-economic situations, accessibility or constraints to opportunities, and public attitudes. It is noted that the multiplicity of identity owes its origin to the young women's experience of abduction. In the bush they were women/girls; child wives, mothers, fighters and porters, with one person taking on multiple identities (Angucia, 2010; McKay 2004; McKay and Mazurana, 2004). In a way therefore the child mothers were torn between their childhood, motherhood and adulthood. Yet their role as mothers demanded a different level of social expectations. So this crisis of identity continued in the return period with the historical circumstances of abduction of the young women acting as a strong obstacle to their marital social integration.

The cultural perceptions of child mothers as adults clouded social support to the girls and in other cases the lack of recognition of the growth and development of the child mothers into young adults made it difficult for them to be effectively supported. This has been exacerbated by interventions which treated the young women as children and not young adults (Stout, 2013). The individuated experience of the young women and how this can be brought to bear on the reintegration process was thus lost. The deterministic approach to support further created more challenges of identity among the young women, compounding their difficulties. It is suggested that in planning interventions for the young women, focus should be made on these issues and intersection of their abduction experience, perception of identity, gender and cultural positioning. Such an approach can only come out if the intersectionality of the experiences of these young women is taken into consideration. 
This study seeks to contextualise the issues under investigation within feminist research perspectives, particularly those aspects which pertains to gendered power relations (Haralambos and Holborn, 2008; Saul, 2003; Nicholson, 1990). Studies have noted demonstrated gender power imbalances in the political economy and socio-economic and cultural circumstances of most communities affected by armed conflict (Frerks et al., 2005; De-Berry, 2004; McKay and Mazurana, 2004). This is the same community in which formerly abducted girl children find themselves returning to (Bukuluki et al., 2008). This study, however, discusses and analyses the issues emerging from the research within an African feminist theoretical positioning which recognises the difference and uniqueness of the African situation and experiences from other social positioning.

Rehabilitation and resettlement support to the formerly abducted child mothers has thus been carried out in a context of ongoing conflict and varied gender relational nuances and perspectives. In this case the framework for support, follow-up and monitoring has taken a different course from the conventional $\mathrm{DDR}$ as the situation has been different. This paper, thus, assumes four distinct phases in the engagement with the formerly abducted child mothers: life in captivity and return; rehabilitation support at reception and rehabilitation centres (RRC), resettlement in the community after rehabilitation; and a long-term reintegration process (developmental phase). The paper recognizes, however, the interrelationships between these four distinct phases. Within the RRC, the support facilities that were available have been premised on the western models built on psychology/psychiatry and recovery from critical events (Ochen and Okeny, 2010). This conceptual framework assumes that the formerly abducted child mothers' situations require interventions in the short term, medium term and long term so as to fully address the enduring impact of the conflict on them and communities (Allen and Schomerus, 2006). Best practices in support to children affected by armed conflict suggest that efforts should be geared at restoring social function and structure to the days before the conflict. Lesson of experiences suggests that where intervention in the lives of the children affected by armed conflict is made, there seems to be a quicker return to normalcy and participation in community activities (McKay, Veale, Worthen, and Wessels, 2010; Fearon, Weinstein, and Humphreys 2009; Boothby, Crawford and Halperin, 2006). Some scholars however question the efficacy of PSS intervention at community level, arguing that changes at personal and individual levels appear to be the more defensible option (Humphrey and Weinstein, 2007).

\section{Findings}

\section{Assessment of Intervention Strategy}

In northern Uganda, the main intervention strategy was to focus on improving the psychosocial functioning of the formerly abducted child mothers and equip them with life skills such as vocational training and IGA support. It was believed that this would enhance their reintegration chances in the community. According to key informants, the major assumption for the interventions was that support to the formerly abducted child mothers would enable them utilise the skills gained to improve their own livelihoods. It was further assumed that the formerly abducted child mothers would accept the vocational training available and on offer by the agency. Although the formerly abducted child mothers were not forced to take on a particular vocational training; the options open to them were quite limited. On the surface therefore, the agencies could claim that there was self-determination of the formerly abducted child mothers to enrol on a particular vocational training or socio-economic activities; in reality however, these were coaxed by the situation into doing what was on offer. This was also confirmed by local civil society and local government informants working with the formerly abducted child mothers. This could possibly explain why many of the formerly abducted child mothers in the long run abandoned the skills learnt and opted for new forms of livelihoods as revealed by the focus groups, individual interviews with young women and key informants' perspectives.

Moreover, one agency worker at decision making position suggested that there is little evidence that the skills learnt have "proved adequate to securing a livelihood". This problem could have perhaps been avoided if the formerly abducted child mothers were genuinely helped to make their own choices after considering available options. In initiatives like training support under income generation activity, there 
was little focus on the self-esteem and socialisation skills as well as the agency and aspirations of the formerly abducted child mothers. It is my view based on analysing the interviews and the testimonies of the formerly abducted child mothers that a better result could have been guaranteed, if considerations were given to the issue of self-esteem.

Consultation also indicated that in the face of dwindling donor funds, development agencies have simply not been able to continue with some project activities and many times projects have ended without the community being prepared or informed about it (poor exit strategy). Consultation with communities in one sub-county revealed:

This organisation [name withheld] came here and carried out certain activities, and I must say they were doing well, mobilising us for development activities, and helping identify opportunities within the community for our own socio economic development. We woke up one morning, however and found them gone, without a word whether they would come back or another agency would replace them (community focus group, Patiko, sub-county, Gulu district)

Such a situation causes incredulity and undermines the principles of continuity and sustainability of development efforts. Moreover in situation where the intervention was aimed at addressing personal social development needs or situations, the young women (formerly abducted child mothers) were left much worse psychologically as their hope would be dashed. It also beggars the question whose interest do these interventions address? And what's the basis for development planning in such a case?

\section{General Limitations of the Interventions for Formerly Abducted Child Mothers}

The general approach to psychosocial programming in northern Uganda seemed to have been uncoordinated with different agencies implementing different approaches in areas of their choice. This did not provide synergy and the benefits of development networking at the local level. as indicated earlier, the interventions were mostly general, not only aimed at addressing needs and situations of formerly abducted child mothers; although specific activities within the project would focus on the situations of formerly abducted child mothers. In order to understand more about the challenges faced and how these impacted on program delivery, some of the key limitations of the interventions are discussed in the proceeding, where we make reference to their implications to resettlement and reintegration of the formerly abducted child mothers:

\section{Inadequate Framework for Reintegration Planning and Support}

Consultation suggests that reintegration programming in northern Uganda is a complex field with a multiplicity of actors from the private not-for-profit sector and also from the public sector. Although initially, UNICEF had instituted a framework for national psychosocial coordination meetings (UNICEF 1998), this has over the years become redundant, overtaken by the agency's current focus on child protection as an intervention strategy. At the district level, the coordination meetings initially covered psychosocial support as a separate issue. Since 2010 however most attention has been paid to child protection programming, resulting in psychosocial (PSS) issues being given less attention. The emphasis on general child protection indicates UNICEF's strategic country focus, and UNICEF is a key leader in child-focused interventions. Even at the community level, support to the current structures appears to have been linked directly to child protection concern, with no direct emphasis on continued, strategic and systematic psychosocial support. Whereas the changing nature of the northern Ugandan context is appreciated, the gradual decline in psychosocial support activities implied reduced funding and interventions for the agencies that initially supported psychosocial activities. here I argue that although the general focus on child protection makes it possible to address rights and needs of orphans and other vulnerable children in the community, the opportunities to support effective reintegration of formerly abducted children, including child mothers might be constricted. There is a high possibility that specific psychosocial needs of the formerly abducted child mothers and their children might actually not be fully 
met by such an approach. Yet interviews with key informants and community consultations suggests that psychosocial needs remains high not just for those that were formerly abducted but the general community whish suffered trauma during the insecurity.

Most interventions in northern Uganda consider the needs and situations of the formerly abducted child mothers within an intervention framework addressing the general needs of communities and other formerly abducted children (FAC). For most development agencies there is no specific budget line or line of activity devoted entirely to the situations of the formerly abducted child mothers. This, therefore, reduced the total resource outlay available for addressing the needs of the formerly abducted child mothers. Concern has been raised about the inadequacy of interventions in addressing the situation of formerly abducted child mothers. Key informants and community focus groups also identified the unique situation of child mothers and the complexity of developing and implementing interventions to address their situation arguing that most of the child mother issues have been ignored at best or only partially addressed. While recognising that not all formerly abducted child mothers have the same levels of needs and challenges, they suggest that those passing through the reception and rehabilitation centres (RRC) tend to be more positive and run more viable income generation activities. It appears, therefore, that those child mothers who did not pass through the RRC seem to be the ones with greatest needs, yet with lesser support opportunities as NGOs tend to follow up mainly its former clients. Development commentators have however, questioned the approaches used in supporting the formerly abducted child mothers with a criticism that development agencies have created dependency among the formerly abducted child mothers.

In my view development agencies have ignored the advice to make
consultation before providing support to the affected group. The paternalistic
assumptions with which they have viewed the young people made them
choose interventions which tends towards a hands-out kind of approach and
little on transferable and reusable skills and gendered analysis (development
worker, Amuru, district).

The problem of dependency comes about because some of the interventions being implemented by a number of development organisations are short-term interventions aimed at enhancing reporting situation to donors about the number of target groups reached. The argument here is therefore that such an approach creates and cultivates dependency among the formerly abducted child mothers instead of empowering them; Empowerment is a gradual and not a one-off process. Perhaps those child mothers who transformed their situation using the support provided could have drawn considerable personal agency to break through. The real needs of the young women are thus not met effectively as activities and initiatives are rushed, leaving little rooms for innovative actions. It is important to note that analysis of programme documents of agencies in northern Uganda also suggest that the interventions aimed at returning children to the community was not that comprehensive. They were mainly resettlement and reinsertion interventions, which only addressed superficial issues within a short planning framework. There was thus no clearly developed framework for long-term reintegration support and in many cases gender and women related needs and situations were not properly handled. In this regard, the community was not effectively prepared to accept children returning from the bush, with the latter facing significant resettlement challenges. Again, the girls who returned without children appear to have been better accepted even among their own families and potential suitors. The current study however, suggests that formerly abducted child mothers have far more challenges compared to both other girls without children and boys, with many of them reporting failure of their families to fully accept them as members of the family.

'The children that we came back with, they are not liked at all, they are not supposed to even touch the neighbors' kids'. 'they showed a lot of dislike for my kids and then even me that is the hardship i found, some relatives even started cutting my clothes and my children's shoes for acts of witchcraft all wanting me to leave there.' FGD GUSCO formerly abducted mothers 
From 2010 up now I am now alone, they and took me to Layibi where I was abducted. I first went to my grandfather, but my grandfather is not a good man because he can talk a bitter language to abuse my children and then my grandfather said I am not the one who told you to come to my home here... Who told you to come here? Even my grandmother told me to leave this place 'because your grandfather is bad' I feel bad about it and I said if I leave I will not come again here. Then I started to rent a house...one room... in our home it was two rooms. I got annoyed and I did not want to quarrel with him and left. I left the place and got one room it was 40,000/= (approx. 11.65 USD) (Formerly abducted child mother, Gulu).

As seen in the above quotations the challenges the young women faced on returning to their communities (family reunion), were severe and yet many of the NGOs did not effectively engage the families or find suitable alternatives for the young women post-reinsertion. Livelihoods and other support provided were not adequate nor were they sustained by many of the child mothers. Other agencies proposed unorthodox interventions which raised concern of other stakeholders such as the case of an international agency recalling formerly abducted child mothers from the community to live in its own centre within Gulu main town in Gulu district. This agency argued that those people needed to be together in town yet it did not have adequate resources to perpetually support the formerly abducted child mothers and their children, or meet all their socio-economic as well as psychosocial needs. Besides, such an approach was at variant with community based reintegration model encouraging greater participation and involvement of the formerly abducted young women in community programmes. The inability of the district leadership to provide effective guidance on an appropriate intervention framework for young people affected by conflict was instructive. If a framework existed, this could have significantly streamlined interventions planning and outcomes. It is possible that the lack of support to effective coordination by the local government could be due to both capacity issues and a blind trust in NGOs and other development agencies as well-meaning, and therefore can do what they consider good for society.

\section{Emergency Orientation of the Interventions}

The context of reintegration was in itself a key limitation in supporting the young mothers returning from rebel captivity. Much of the programming has been on the emergency and therefore little consideration for long term reintegration, if any, was actually made. For example, whereas development agencies carried out sensitisation programmes, these have not been very effective in addressing stigma, which remains a critical challenge for reintegration. Another contextual challenge was that reunion of formerly abducted child mothers took place in an unnatural context, internally displaced persons (IDP) camps, which had other socio-economic and political challenges such as poverty. In this case therefore, the success of reintegration programme was also dependent on the context and not only the activities of the PSS agencies. Although IDPs later returned home (especially after 2007), support to formerly abducted child mothers continued along the same emergency model, whether from state or non-state agencies alike. Moreover, supporting formerly abducted child mothers became much more difficult and complex when affected communities began to perceive any direct support as a reward for participation in rebel activity. Yet providing support to everyone within the community was not even economically, socially and administratively tenable. In a situation where every household has been affected in one way or another, how do you address reparation issues, for example?

\section{Discussion and Interpretation of the Findings}

A critical reflection on the nature and dynamics of the RRR interventions in Northern Uganda brings important lesson to bear in international humanitarian and development programming. One of the key lessons is that when designing and implementing rights-based approaches, the target group should not be looked at as objects of charity but empowered to lay claims on their rights, with the children and young people considered as key actors. It should be recognised that achieving significant changes in one aspect of life requires interventions in other related areas (systems approach and holistic coverage). However, the analysis of interventions in Northern Uganda suggests otherwise. Limitations in resources (especially financial resources), management weaknesses and other contextual factors (e.g. coordination challenges) have constrained achievements of holistic development outcomes for children and young people within 
the region. There is also a view however that resource endowments spent in northern Uganda was quite significant and should have registered substantial meaningful change. This view therefore suggests other factors as explaining the inability to register the changes sought. A look into some of these arguments and factors comes in handy here.

A view among development commentators is that many of the interventions developed to support the formerly abducted child mothers were fragmented and limited and did not therefore address all young people's situated challenges (Abola, Omach, Anena, Ochen and Barongo, 2009; impact options limited 2010; Allen and Schomerus 2006). Writing in favour of a holistic approach to support formerly abducted children, P'Olak (2005) notes that addressing therapeutic needs of the girls without equal and perhaps more attention to the contextual problems of poverty could negatively impact the reintegration process. While poverty was pointed out here it is a view espoused in this paper that security and therefore conflict sensitivity should be at the heart of planning such interventions, for them to be successful.

As earlier indicated, it has been reported that a number of NGOs wound up their operations and activities in northern Uganda. While the majority have been humanitarian agencies whose mandates might not cover the recovery period; there is evidence that many development agencies also wound up their activities. Commentators in the region have expressed the opinion that it appeared as if development agencies were winding up their activities due to their fear to create real and meaningful change in the lives of the communities (Abola, Omach, Anena, Ochen and Barongo, 2009). It is important to note that the interventions during the emergency period were primarily aimed at sustaining life and promoting access to basic needs. Few of the interventions of humanitarian actors in the region went beyond sustaining life and improving accessibility to basic needs. The decision to withdraw or minimise intervention is against good practices in humanitarian responses. These decisions should ideally be informed by significant improvement in the indicators of well being based on the thematic areas of intervention (Spheres Project, 2004).

Analysis of the current situation in northern Uganda indicates the dilemma of programming in relation to the changes in the context from an active and volatile emergency period to a lull in fighting also referred to as recovery by government and civil society agencies (Bailey, Pavanello, Elhawary and O'Callaghan, 2009). In the current study stakeholders raised concerns that while the context had changed, development agencies were not provided with guidelines on addressing the new challenges in the recovery period. In some of the cases where programming guidance eventually came, it was more of public servants / technical staff's opinion than well-thought out local and central government's position (Abola, Omach, Anena, Ochen and Barongo, 2009). While this generally applied to all development interventions, there is no evidence that the NGOs and other actors supporting the formerly abducted child mothers received any special support. Bailey, Pavanello, Elhawary, and O'Callaghan (2009) recognise the programming challenges occasioned by "early recovery" interventions and observe that the concept is new with few locations where lessons can be drawn from.

Interventions in the recovery period indicate a preoccupation with blue print interventions. Such were the interventions whose outcomes involved the creation of a physical asset or quantifiable outputs. This preoccupation with hardware development interventions without the process aspects leaves much to be desired. It is therefore visible that emphasis on the process of engagement with stakeholders including direct target groups as key resources in the development activity seems to have been bypassed by current recovery programming. Recovery programming refers to all activities aimed at supporting the process of formerly displaced communities rebuilding their lives within their villages post IDP Camps. This paper argues, however, that if interventions aimed at building bridges between recovery and the development phase then there was a need to ensure that the recovery phase gets adequate funding.

The main development planning framework for northern Uganda is the peace, recovery and development plan (PRDP) which is government's three-year recovery development strategy for the region, beginning in the year 2008. Nevertheless, actual resource allocations in 2010/2011, for example, for implementation do not seem to provide any clear commitment of resources on the part of government for such activities. Government has practically left reintegration issues to be addressed by NGOs and other development agencies, yet these also have funding challenges (Abola, Omach, Anena, Ochen and Barongo, 2009). As a result, the momentum built up during the period of active emergency (early 1990s to 2006) in 
interventions programming in the region has slowed down with serious repercussion for service delivery to the community.

Furthermore, contrary to what is stipulated within the PRDP, interviews with PSS agencies in northern Uganda do not seem to suggest that "technical standards for programme intervention" have been established (Republic of Uganda, 2007, p.102). However, this has been suggested as one of the initial actions in supporting reintegration interventions in the context of the PRDP. My analysis of the reintegration strategies within PRDP and its discourse suggest that the framers of the document were still engrossed with reinsertion interventions. However, debates within the reintegration literature and the contextual changes in northern Uganda suggest the need for a radical rethink on how PSS programming in the region is executed. In other words, the recovery and development intervention requires something different from what has been tried before and found to be inadequate. The emerging issues suggest that the government is thus practically not doing enough to proactively address genuine development issues for the conflictaffected region, especially for children and women coming out of conflict.

The current study contributes to a greater appreciation of indigenous cultural positions integration of gender issues in development. This study demonstrates that African culture and patriarchy does not necessarily imply oppression to women and children. Evidence of social institutions which enhance women's protection were mainly unreported or ignored due to essentialist approaches and generalisation of the Acholi culture as being patriarchal and therefore intimidating and oppressive towards women and children. However, a nuanced analysis of these cultural aspects and social institutions might show the presence of space for rights fulfilment for both women and children (Oyewumi, 2000; Mikell, 1995). Current literature on children in conflict recognises the positive role of culture and social institutions in shaping a society which respects the interests of children (e.g. Bisell et al 2012; Wessels, 2009; Shepler, 2005; Oyewumi, 2000; Mikell, 1995). It is possible that it is the abuse of culture and parochial interests of sub groups (in this case the rebels) which generate women and children's oppression, exploitation and subjugation.

\section{Conclusions}

This paper has presented a broad reflection on the interventions for formerly abducted child mothers. It was argued that several assumptions which underlie the interventions were inappropriate and did not look at the young women as having agency, and many of the interventions were thus simplistic and did not adequately prepare the young women to a generate effective livelihoods and manage other challenges of reintegration. It analysed the prevailing intervention assumptions as well as the core limitations and challenges of development programming within the complex context of northern Uganda. General limitations of the interventions included: inter-agency competition; absence of a well-thought framework for reintegration support; limitations of resources available for formerly abducted child mothers-only interventions; lack of a unified framework for psychosocial support. Other challenges included: the rigidity of the donors in funding long term development interventions; the preference of donors for short term projects; and inability of any local organisations to procure resources on their own without going through intermediary international development agencies. Yet other challenges relate to perceptions of support to formerly abducted child mothers as a reward for rebellion; reunion of the formerly abducted child mothers in a volatile context; and withdrawal of development agencies from northern Uganda. The lack of articulation of clear standards of changes and the determination of effective me benchmarks constricted lesson learning and sharing of experiences within the intervention context.

The paper also highlighted issues pertaining to the challenges of transiting from the emergency to a recovery context in terms of planning and programming philosophies. While analysis focused mainly on northern Uganda, lessons from elsewhere were also explored. I also made the case for ensuring that interventions into the lives of the formerly abducted child mothers should be aimed not only at meeting their everyday needs but also at ensuring that they have equal rights to socio-economic development resources. The interventions should also awaken their social and political consciousness to ensure that their voice is heard in order to influence the socio-political and economic direction of their communities 
and society as well as consideration of the key gender nuances which have ramifications for sustainable reintegration at community levels. Yet critical analysis of these actions and programs of the government and non governmental agencies indicates that the important issue of intersectionality and how the precarious situations and multiple vulnerabilities of the young women impinge on their reintegration. It should be noted that child motherhood, low levels of education, and warped cultural interpretations the process by which the young women could live a much more fulfilled and attain their potentials. The successes of any intervention therefore involving the child mothers will have to factor in all these issues and the strengths of the child mothers.

In developing an effective model to support the development programming for formerly abducted child mothers to achieve the above, there is need to think about long-term, rigorous and phased interventions focusing on meeting development rights of the formerly abducted child mothers, their children and their communities. Such a broader outlook would in my view be more effective in addressing among others negative social opinions about the formerly abducted child mothers, while remaining relevant to security sector issues and conflict sensitivity.

\section{References}

Abola, C., Omach, P., Ochen, E. A., Anena, C. \& Barongo, A. (2009). Evaluation of Norwegian development cooperation through Norwegian non-governmental organizations in northern Uganda (2003-2008). Oslo: the Norwegian agency for international development, evaluation report 3/2009

Allen, T. \& Schomerus, M. (2006). A hard homecoming: lessons learnt from the reception centre processes in northern Uganda. An independent study commissioned by USAID and UNICEF. Retrieved from: http://pdf.usaid.gov/pdf_docs/pnadi241.pdf. [Accessed the 30 ${ }^{\text {th }}$ of September 2010].

Angucia, M. (2010). Broken citizenship: formerly abducted children and their social reintegration in northern Uganda. Amsterdam: Rosenberg publishers.

Bailey, S., Pavanello, S., Elhawary, S., \& O’Callaghan, S. (2009). Early Recovery: an overview of policy debates and operational challenges. Humanitarian policy group working paper, November 2009. London: Overseas Development Institute.

Bainomugisha, A. (2011). Child soldiers in northern Uganda: an analysis of the challenges and opportunities for reintegration and rehabilitation. Unpublished $\mathrm{PhD}$ thesis university of Bradford.

Boothby, N., Crawford, J. \&. Halperin, J. (2006). 'Mozambique child soldier life outcome study: lessons learned in rehabilitation and reintegration efforts'. Global public health, February; 1(1), pp.87-107.

Corbin, J. N. (2008). 'Returning home: resettlement of formerly abducted children in northern Uganda'. Disasters, 32 (2), pp. 316-335

Crenshaw, K. (1994). Mapping the Margins: Intersectionality, identity politics and Violence against women of colour. In: Fineman, M. \& Mykituk, R. eds., The Public Nature of Private Violence. New York: Routledge, pp. 93-118.

De-Berry, J. (2004). The Sexual Vulnerability of Adolescents Girls during Civil War in Teso, Uganda. In: Boyden, J. and De Berry, J. eds. Children and youth on the frontline: ethnography, armed conflict and displacement. New York: Berghahn Press, Pp. 45-62.

Dolan, C. G. (2006). Uganda strategic conflict analysis; Swedish International development assistance (SIDA), department for Africa. Accessed on the $23^{\text {rd }}$ may 2009 from: http://www.sida.se/sida/jsp/ sida.jsp?d=118\&a=30613\&language $=$ us_en

Dolan, C. \& Hovil, L. (2006). Humanitarian protection in Uganda: a Trojan horse? Retrieved august 20, 2010 from the website: http://www.odi.org.uk/resources/details.asp?id=288\&title=humanitarian- 
protection-Uganda-trojan-horse

Fearon, J., Weinstein, J., \& Humphreys, M. (2009). Can development aid contribute to social cohesion after war? Evidence from a field experiment in post-conflict Liberia. Paper presented at the American Economic Association annual meeting.

Frerks, G. Bouta, T. \& Bannon, I. (2005). Gender conflict and development. Washington D.C: the World Bank.

Harvey, R. (2003). Children and armed conflict: a guide to international humanitarian and human rights laws. Essex: international bureau for children's rights.

Honwana, A. (2006). Child soldiers in Africa: Philadelphia: University of Pennsylvania press.

Humphreys, M. \& Weinstein, J. M. (2007). 'Demobilization and reintegration'. Journal of Conflict Resolution 51, pp. 531-567.

International Labour Organization. (1995). Reintegrating demobilized combatants: the role of small enterprise development, entrepreneurship and management development branch (Geneva: international labour office).

Impact Options Limited (2010). Reintegration of returnees, ex-combatants and other war affected persons in the communities of Gulu and Amuru districts, northern Uganda. A research report submitted to Gulu support the children organization (gusto).

Jones, A. (2009). Social Marginalisation and Children's Rights: HIV affected Children in the Republic of Trinidad and Tobago. Health and Social Work. Special Issue on Health and Inequality. NASW Press, Washington DC.

King, N. (2012). Using templates in the thematic analysis of text. in: Cassels, C. \& Symon, G. eds., essential guide to qualitative methods in organizational research. London: Sage, pp.453-478.

Machel, G. (2001). the impact of war on children: a review of progress since the 1996 united nations report on the impact of armed conflict on children. Basingstoke: Palgrave Macmillan.

Maina, G. M. (2010). An Analytical Study of the Reintegration Experience of the Formerly Abducted Children in Gulu, Northern Uganda. Unpublished PhD thesis, University of Bradford.

Mazurana D. \& Carlson, K. (2006). The girl child and armed conflict: Recognizing and addressing grave violations of girls' human rights. Paper prepared for the meeting of the UN division for the advancement of women (daw) in collaboration with UNICEF expert group meeting elimination of all forms of discrimination against the girl child, Florence Italy $25^{\text {th }}-28^{\text {th }}$ September 2006; Retrieved from http://www.un.org/womenwatch/daw/egm/elim-disc-viol-girlchild/expertpapers/ep.12\%20 mazurana.pdf

McKay, S. (2004). 'Reconstructing Fragile Lives: Girls Social Reintegration in Northern Uganda and Sierra Leone'. Gender and Development, November, 12 (3), pp.19-30.

McKay, S. \& Mazurana, D. (2004). Where are the Girls? Girls in Fighting Forces in Northern Uganda, Sierra Leone and Mozambique: Their Lives During and After War; Montreal: Rights and Democracy.

Mckay, S., Veale, A, Worthen, M, \& Wessels, M. (2010). Community-based reintegration of war affected young mothers: participatory action research in Liberia, Sierra Leone and northern Uganda. Retrieved on October 2, 2010 from the website: http://www.crin.org/docs/par_report.pdf

Mikell, G. (1995). 'African feminism: Towards a New Politics of Representation'. Feminist Studies. Summer, 21 (2), pp 405-424. Retrieved from http://www.jstor.org/stable/3178274 [Accessed on 
the $22^{\text {nd }}$ February 2011]

Ochen, E. A \& Okeny, R. (2011). Supporting Children Affected by Armed Conflict in Northern Uganda: Muse and Reflections from the Activities of Gulu support the Children Organization (gusco) 1994-2010. Reflection: narratives of professional helping. Special issue, the heart of justice: social work innovations in Africa, winter 17 (1) pp.17-27.

Oloka-Onyango (2001). Constitutionalism in Africa: yesterday, today and tomorrow. In: OlokaOnyango, J. Ed. Constitutionalism in africa: creating opportunities, facing challenges. Kampala: fountain publishers pp.1-17

Omach, p (2010a). Regionalisation of rebel activities: the case of the lord's resistance Army. In Okumu, W. \& Ikelegbe, A. Eds. Militias rebels and islamist militants: human insecurity and state crises in Africa. Pretoria: institute of strategic studies, pp.287-312.

Omach, P. (2010b). Politics, conflict and peace building in Uganda. Dusseldorf: VDM Verlag academic publishing.

Omara-Otunnu, A. (1987). Politics and the military in Uganda, 1890-1985. Oxford: Mcmillan press.

Omara-Otunnu, A. (1992). 'The struggle for democracy in Uganda'. Journal of modern african studies, September, 30(3) pp. 443-463

Oyewumi, O. (2000). 'Family Bonds/Conceptual Bonds: African Notes on Feminist Epistemologies'. Signs, Summer, 25 (4), pp.1093-1098

Paquin, J. \& Saideman, M. (2008). Foreign intervention in ethnic conflicts mimeo. Retrieved from: http://www.humansecuritygateway.com/documents/isa_foreigninterventionethnicconflicts.pdf [accessed on the $24^{\text {th }}$ February 2011]

P'Olak, A. (2005). 'Psychological impact of war and sexual abuse on adolescent girls in Northern Uganda'. Intervention, 3 (1) pp.33-45.

Ramazanoglu, C. \& Holland, J. (2002). Feminist Methodology: Challenges and Choices. London: Sage.

Refugee Law Project (2004). Behind the violence: causes, consequences and the Search for solutions to the war in northern Uganda, Kampala, and refugee law project working paper no. 11.

Shepler, S. (2005). 'The Rites of the Child: Global Discourse of Youth and reintegrating Child Soldiers in Sierra Leone'. Journal of Human Rights, 4, pp.197-211.

Singer, P. W. (2006). Children at War. Berkeley (la): University of California press.

Smith, D. (1998). Review article: Anthony Giddens and the liberal tradition. British Journal of sociology volume no.49 issue no 4 December 1998, pp. 661-669.

Stout, K. (2013). Silences and Empty Spaces: reintegration of girl chid soldiers in Uganda: gendering problems and Engendering solutions. LLM Thesis University of Toronto

United States Institute of Peace (2010). Uganda/lord's resistance army peace negotiations. Retrieved September 13, 2010 from the website: http://www.usip.org/resources/Ugandalords-resistancearmy-peace-negotiations;

UNICEF (1998). Northern Uganda Psychosocial Needs Assessment. Kampala: United Nations children fund Standards. Available at: http://www.unddr.org/iddrs/02/download/iddrs_210.pdf. [Accessed on $15^{\text {th }}$ October 2011]

United Nations (2008). Committee on the rights of the child's forty Ninth session: consideration of reports submitted by state parties under article 8 of the optional protocol to the convention on the 
rights of the child on the involvement of children in armed conflict. Accessed from www.un.org/crc on the 25th of January 2009. International organisation, 41, (3), pp. 335-370.

Wessells, M. (2006). Child Soldiers: from Violence to Protection. Boston: Harvard University Press.

\author{
About the Author \\ Dr. Eric Awich Ochen is a faculty in the College of Humanities and Social Sciences, School of Social \\ Sciences, Makerere University.
}

